\title{
LA DINÁMICA EXTRACTIVA DEL CAPITAL COMO AMENAZA PARA LA REPRODUCCIÓN DE LA VIDA. ALGUNAS REFLEXIONES DESDE LA ECOLOGÍA POLÍTICA Y EL MARXISMO EN TORNO A LA NOCIÓN DE "PROYECTOS DE MUERTE"
}

Francisco Javier Hernández Hernández

Benemérita Universidad Autónoma de Puebla (BUAP)

\begin{abstract}
RESUMEN
A lo largo de la última década, la noción que clasifica a los diversos proyectos de carácter extractivo como algo antagónico a la vida, bajo la categoría común de "proyectos de muerte" ha cobrado relevancia tanto en su uso como en su extensión en prácticamente todos los países de América Latina, principalmente por parte de comunidades, organizaciones y colectivos que se oponen a la minería, el fracking, las hidroeléctricas o algún otro proyecto de carácter extractivo. En este sentido, cabe reconsiderar la importancia de la noción dicotómica vida-muerte en el contexto de las luchas contra los otrora llamados "megaproyectos" no sólo como una categoría de lucha o una categoría politizada, sino también como una clave para el análisis de las repercusiones socio-ecológicas que los proyectos extractivos causan sobre las diversas formas de vida. El presente trabajo consiste en una serie de reflexiones teóricas desde la ecología política y el marxismo en torno a cómo la dinámica del capital transforma radicalmente la vida humana y no humana para hacerla susceptible de ser subsumida a la lógica del valor, refuncionalizando los flujos de materia-energía del trabajo vivo, los valores de uso y la naturaleza.
\end{abstract}

Palabras clave: Metabolismo. Ecología Política. Marxismo. Vida. Muerte.

\section{THE EXTRACTIVE DYNAMICS OF CAPITAL AS A THREAT TO THE REPRODUCTION OF LIFE. SOME REFLECTIONS FROM POLITICAL ECOLOGY AND MARXISM AROUND THE NOTION OF "DEATH PROJECTS"}

\begin{abstract}
Over the last decade, the notion that classifies the different projects under the common label of "death projects" and, therefore, to the extractive industry as something antagonistic to the life, it has become relevant in both ways, in its use and its extension in almost all the countries of Latin America, mainly by communities, organizations and colectives that oppose to the minning, the fracking, the hydroelectric or some other extractive project. It is worth reconsidering the importance of the life-death dichotomy in the context of the struggles against the so-called "megaprojects" not only as a category of struggle or a politicized category, but also a key to the analysis of the socioecological repercussions that extractive projects cause on different forms of life. In this sense, the present work consist of a series of theoretical reflections from political ecology and Marxism about how the dynamics of capital radically transforms human and non-human life to make it susceptible
\end{abstract}

\footnotetext{
* El presente trabajo es una síntesis de algunas de las reflexiones centrales de mi tesis "Vida, muerte y lucha en la Sierra Norte de Puebla. Una reflexión en torno a la Asamblea de los Pueblos Maseual, Totonaku y Mestizo en Defensa de la Vida y el Territorio", presentada a examen de titulación en enero de 2019 para obtener el grado de Maestro en Sociología por el Instituto de Ciencias Sociales y Humanidades “Alfonso Vélez Pliego" de la Benemérita Universidad Autónoma de Puebla (ICSyH-BUAP), principalmente de los apartados 1.1.2. y 2.6.
} 
to being subsumed to the logic of value re-functionalizing the matter-energy flows of living labor, the values of use and nature.

Keywords: Metabolism. Political Ecology. Marxism. Life. Death. 


\section{INTRODUCCIÓN}

Ante la proliferación de proyectos mineros, hidrocarburíferos e hidroeléctricos (entre otros de corte extractivista) acaecida a lo largo de las dos últimas décadas en América Latina, numerosos pueblos y comunidades indígenas y campesinas de la región han desplegado diversos procesos de resistencia y articulación en defensa de sus territorios. Dichos sujetos de lucha han ido coproduciendo un sentido común de disidencia desde el cual se enuncia a los distintos proyectos de corte extractivista como algo antagónico a la vida, tanto en la enunciación de consignas como "SI a la VIDA, No a la Mina", "Ríos para la VIDA, NO para la MUERTE", "La Vida vale más que el Oro", como en la bajo la etiqueta común de "proyectos de muerte". Más que una metáfora bien aplicada con una gran potencia simbólica y movilizadora, se considerará aquí que, incluso en términos materiales (aunque no solamente), los distintos proyectos extractivos representan una amenaza para la vida en más de un sentido.

Pero ¿de qué manera podemos abordar que los proyectos extractivos son algo antagónico a la vida, a tal punto que la noción "proyectos de muerte" puede ser considerada como algo real, material y no meramente metafórico? Si bien el espacio dispuesto para este artículo no permite desarrollar con detalle las claves centrales desde las cuales entendemos la vida, me limito a enunciar de manera sintética algunas de las reflexiones realizadas al respecto.

Desde una perspectiva sistémica, Fritjof Capra (1998) propone que la vida no puede ser entendida desde la perspectiva del individuo, sino que toda forma de reproducción implica la realización de una serie de relaciones e intercambios metabólicos en constante flujo entre la diversidad de seres vivos, comunidades bióticas, en y con el entorno geográfico "inorgánico" y los elementos abióticos ${ }^{1}$, a manera de trama o tejido.

En el caso de los grupos humanos, a diferencia de otros animales, la forma en la que se relacionan con la naturaleza que les es externa para lograr satisfacer sus necesidades de reproducción no está determinada por el instinto. En este sentido, Bolívar Echeverría (2010) retoma la noción sartreana de que "el hombre está condenado a su libertad", por lo cual, el ser humano requiere - y tiene la capacidad - de darse forma, tanto en la manera como lleva a cabo las relaciones metabólicas con la naturaleza que le es externa, como en la manera en que se organiza y se

\footnotetext{
${ }^{1}$ Dentro de los aspectos del entorno geográfico "inorgánico" y los elementos "abióticos" consideramos no sólo los elementos considerados desde las ciencias como "no vivos", como el agua, los nutrientes y minerales presentes en la tierra y la roca, etc., sino también los ciclos de los hidrológicos, el curso de los vientos, la diversidad topográfica, la cantidad de radiación solar en ciertas épocas del año, entre otros aspectos que condicionan los flujos y relaciones del metabolismo de la trama de la vida en determinada región o territorio.
} 
conforma como sujeto social. Tanto la forma como las relaciones, están a su vez mediadas por el lenguaje y lo simbólico, en el proceso "permanente y en marcha" de significación del mundo 2 (Gutiérrez et al., 2016). Las relaciones de producción, distribución, consumo, reproducción, cooperación comunicación y significación, así como las de poder y dominación, es decir, todas las relaciones entre sujetos desplegadas al interior del proceso de reproducción social, así como las relaciones entre sujetos humanos y la naturaleza no humana, parten del establecimiento y conformación-transformación ${ }^{3}$ de ciertas relaciones metabólicas.

Podemos decir que toda actividad humana implica una transformación, alteración o modificación metabólica en mayor o menor medida ${ }^{4}$ sobre la trama de la vida ${ }^{5}$ Toda forma y proceso de reproducción humana como es una forma de relación - o conjunto de relaciones - geosocio-metabólica ${ }^{6}$, pues implica el establecimiento de determinadas relaciones de intercambio y transformación de materia-energía (metabolismo), así como de producción y consumo de naturaleza, relaciones sociales y objetos con valor de uso.

Sin embargo, no todas las sociedades y sus respectivos modos de producción transforman o alteran por igual las relaciones metabólicas a través de la trama de la vida. Al respecto, Jason Moore en su capitalism in the web of life (2015) refiere que las relaciones socio-metabólicas del capital han trastocado radicalmente el metabolismo de dicha trama por lo que podemos hablar ya de una nueva era geológica denominada capitaloceno.

Pero ¿qué tiene qué ver todo esto con los nuevos ciclos de despojo y devastación de las formas y condiciones de la reproducción de la vida ante la avanzada de la frontera extractivista y la intensificación de su capacidad destructiva?

El presente artículo consiste en una serie de reflexiones teóricas en torno a la forma en la que el capital actúa modificando y trastocando radicalmente los flujos metabólicos de la trama de la

\footnotetext{
${ }^{2} \mathrm{Y}$ en sentido inverso, lo simbólico, el lenguaje y los procesos de significación están condicionados y mediados por las relaciones materiales. En este sentido, no podemos escindir lo simbólico de lo material, sino que serán considerados como dos aspectos del mismo proceso de reproducción social.

3 Utilizo el par conformación-transformación siguiendo algunas de las nociones sartreanas retomadas tanto por Gutiérrez, Navarro y Linsalata (2016) como por Echeverría (1998, 2010), en el sentido de que la forma y las relaciones establecidas - la conformación - no son algo dado, de una vez y para siempre, sino que requieren de una reactualizacióntransformación constante, como proceso permanente y en marcha.

${ }^{4}$ Respecto a los momentos de la historia de la tierra previos a la aparición del homo sapiens, o respecto a épocas en regiones específicas, previo a la llegada o asentamiento de grupos humanos.

${ }^{5}$ Transformación no necesariamente en términos destructivos.

${ }^{6}$ Geo-socio-metabólico refiere al metabolismo social, contemplando los aspectos de la naturaleza no humana que intervienen en determinado proceso metabólico, o que se ven afectados (en el caso de las transformaciones y/o fracturas metabólicas). Interpretación propia con base a lo expresado por Horacio Machado Aráoz, durante comunicación personal, 2018. A pesar de haber revisado la bibliografía disponible del autor, si bien utiliza en textos el término "sociometabólico" no encontré ninguna referencia en donde utilizara el prefijo "geo" en dicho contexto, por lo que si bien, la categoría no es invención propia, la interpretación respecto a lo expresado por Horacio es responsabilidad de quien esto escribe.
} 
vida, refuncionalizándolos para que la materia y la energía de las formas de vida humana y no humana (la trama de la vida en su conjunto) sean susceptibles de ser incorporadas a la lógica de acumulación, valorización del valor y producción de mercancías.

El argumento central de este texto es el de que la dinámica de reproducción del capital es eminentemente extractivista en un sentido amplio del término. Si bien, nuevamente por cuestiones de espacio me es imposible desarrollar a profundidad el por qué los proyectos extractivos son proyectos de muerte, el objetivo de este artículo es el de poner sobre la mesa de discusión un posible punto de partida - entre muchos otros - para una reflexión crítica tanto de las relaciones del capital mismo, como de su lógica extractiva que le es inherente.

Para comprender la forma en la que dicho metabolismo se ve transformado y modificado por el capital, parto - siguiendo a Marx - de la figura elemental de este modo de producción: la mercancía.

\section{LA FORMA MERCANCÍA COMO PUNTO DE PARTIDA}

En las sociedades (y territorios) donde domina el modo de producción capitalista, los objetos con valores de uso o "riqueza", dice Marx, "se presentan como un "enorme cúmulo de mercancías", y la mercancía individual como la forma elemental de esta riqueza (Marx 2014, p.43)”. El bien producido como mercancía, a diferencia de los objetos con valor de uso producidos bajo otras relaciones sociales y de producción, posee un doble carácter: el de ser un objeto que tiene la cualidad de satisfacer una necesidad humana, un valor de uso; y el de poseer una cualidad de equivalencia cuantitativa respecto al resto de mercancías, que le permite ser intercambiada indiscriminadamente por cualquier otra mercancía (valor).

La forma mercancía y su particularidad de ser valor de uso y valor a la vez, conlleva a la manifestación fetichizada de los objetos producidos bajo esta forma, es decir, mediante una "relación social general de producción [que] consiste en comportarse frente a sus productos como ante mercancías, o sea valores, y en relacionar entre sí sus trabajos privados, bajo esta forma de cosas (Marx 2014, p. 96)". Al respecto, Marx desarrolla su concepto de fetichismo para referirse al fenómeno provocado por la forma mercancía, que implica, por una parte, que los objetos producidos bajo dicha forma se presenten en el mercado como un conjunto de valores, 
esvaneciendo en apariencia sus cualidades concretas y materiales, así como los trabajos concretos cualitativamente distintos que la constituyen ${ }^{7}$.

A grandes rasgos, el valor de una mercancía consiste en la cantidad de trabajo abstracto e indiferenciado, de acuerdo a la media del tiempo de trabajo que, en determinada sociedad con determinada tecnología y cierto grado de organización del trabajo, se requiere para producir determinada mercancía: el tiempo socialmente necesario. A diferencia de los objetos producidos como meros valores de uso, cuyo fin último es el de satisfacer alguna necesidad humana en determinada sociedad, la razón de existencia de una mercancía, el móvil de su producción, es el de ser un bien producido para su intercambio o venta en el mercado, para generar mediante su venta una ganancia, es decir, la diferencia del valor de su venta respecto al valor del costo de su producción. El origen de esta ganancia proviene en buena parte del trabajo impago al trabajador, es decir, que buena parte del valor producido en un día de trabajo por un trabajador - o determinada cantidad de trabajadores - es apropiado por el capitalista, poseedor de los medios de producción. Este trabajo impago, el plusvalor, refiere a la cantidad total de valor producido, menos el trabajo pago al trabajador bajo la forma salario (Marx, 2014).

Parte de este plusvalor producido deberá ser reinvertido por el capitalista al proceso de producción, transformándolo en capital: nuevos medios de producción y trabajo asalariado. El ciclo aquí vuelve a repetirse al poner en marcha trabajo y medios de producción - incorporados a los preexistentes -, con el fin último de producir nuevamente una mayor cantidad de valor (valorización del valor). El móvil de la producción capitalista es la producción de plusvalor, para cuya realización es indispensable la venta de mercancía que permita una ganancia lo más grande posible. Por ello, los capitalistas individuales como representantes del capital en su conjunto, procuran a toda costa reducir los costos de producción, para lo cual es condición indispensable adquirir "recursos" humanos y naturales baratos, mediante la optimización e intensificación de las formas de explotación de la naturaleza humana (trabajo) y no humana (naturaleza) ${ }^{8}$.

\footnotetext{
${ }^{7}$ El fenómeno del fetichismo de la mercancía es más complejo, e implica además que, puesto que la producción está encaminada a la producción de objetos como mercancías para su intercambio, y puesto que en dicho proceso de intercambio la mercancía importa respecto al valor que encierra en sí y no a su valor de uso, los objetos (que buscan a toda costa ser vendidos y comprados) parecieran establecer relaciones sociales entre sí, mientras que los sujetos se presentan como meros poseedores de mercancías, estableciéndose así relaciones cósicas entre sujetos, y relaciones sociales entre cosas. Este aspecto del fetichismo será dejado de lado en este análisis, centrándonos en cómo los objetos producidos como mercancías se manifiestan como un conjunto de valores, desvaneciéndose en la inmediatez los valores de uso y los trabajos concretos que le dieron forma.

${ }^{8}$ Jason Moore (2015), retoma de George Caffentzis la categoría de "work-energy" para referir a la energía y la materia extraída en las relaciones de producción capitalista, tanto a la naturaleza humana (bajo la forma trabajo) como no humana (materia-energía de la naturaleza no humana). Respecto a la intensificación de la explotación de la naturaleza humana y no humana profundizaremos más adelante.
} 
A pesar de que, en una sociedad sujeta a las relaciones sociales y de producción capitalista, la importancia de los objetos producidos como mercancías radique en su cualidad de ser portadoras de valor; los objetos producidos no pueden prescindir de su condición de valores de uso. Ni el sistema de mercado, ni los poseedores del capital pueden prescindir de la materialidad concreta de la riqueza 9 . De la misma manera que el valor de uso - un objeto producido para satisfacer una necesidad humana - sólo se ve realizado una vez que es consumido, el valor de una mercancía - un objeto producido para su venta - sólo se ve realizado una vez que ha sido vendido. Para que un objeto pueda ser vendido a un comprador, el producto debe ser percibido como útil: el valor de uso debe de ser percibido de acuerdo al sistema de necesidades de una sociedad.

El capital no puede prescindir de la materialidad de los objetos y sus valores de uso, ni de la fuerza de trabajo humano ${ }^{10}$, ni de la materia y energía de la naturaleza no humana a partir de las cuales se producen las mercancías. Puesto que la producción de cualquier objeto con valor de uso incluyendo las mercancías con su doble carácter de valor de uso y valor - requieren del despliegue del trabajo sobre la materialidad de la naturaleza no humana; y debido a que, en aras a la generación de ganancia y plusvalor el capital requiere de aumentar gradualmente el ritmo de la producción, mediante la intensificación de la explotación de la energía de la naturaleza humana y no humana. El capital, en su proceso de reproducción requiere de organizar la naturaleza humana y no humana, de la cual depende.

El capitalismo, al tiempo que un modo de producción de riqueza material (bajo la forma mercancía) es una forma específica de geo-socio-metabolismo. Para que la naturaleza no humana (recursos naturales) y humana (trabajo) sean susceptibles de ser convertidos en mercancía, el capital requiere de la producción - y su reproducción ampliada - de las condiciones para dicha forma de producción (O, Connor 2001) lo cual logra transformando el metabolismo de la trama de la vida mediante la realización de separaciones e interposición de mediaciones.

De la misma manera en que la forma en la que los sujetos dan forma a su socialidad mediante la producción y consumo de los bienes producidos - que implica el establecimiento de determinadas relaciones metabólicas con la naturaleza no humana - a partir de la cual irán dando forma a su socialidad, produciendo y consumiendo la forma de su condición comunitaria de existencia (Linsalata 2011; Gutiérrez, Navarro \& Linsalata, 2016); la manera en la que determinada

\footnotetext{
${ }^{9} \mathrm{Ni}$ siquiera en lo referente a productos más efímeros, menos tangibles o en apariencia más abstractos, como lo son los servicios en general, los servicios y productos digitales e informáticos como las aplicaciones y los programas para ordenador, o los servicios de transacciones bancarias remotas. Dichas mercancías siempre están respaldadas y funcionan con la base de una materialidad, tanto del trabajo humano como de la naturaleza no humana.

10 A pesar de la gradual y exponencial automatización de los procesos de producción que ha ido desplazando paulatinamente la fuerza humana de trabajo.
} 
sociedad en la que domina el modo de producción capitalista da forma a su socialidad, parte de la forma de producción y consumo de los bienes producidos bajo la forma mercancía. El Capital de Marx es, en buena parte, una exposición de cómo la forma mercancía, su modo de producción específico y las relaciones sociales que produce; tiende a condicionar y someter a su lógica gran parte de los aspectos de la vida social.

\title{
2. TRANSFORMACIONES METABÓLICAS DEL CAPITAL A TRAVÉS DE LA TRAMA DE LA VIDA: SUBSUNCIÓN DE LA NATURALEZA HUMANA Y NO HUMANA
}

El capital, para su reproducción, requiere del establecimiento de ciertas relaciones metabólicas, sociales y naturales bajo una forma específica que le permita tener a su disposición fuerza de trabajo humana y materia-energía de la naturaleza para la producción de mercancías.

La condición necesaria para que dicho trabajo-energía social-natural esté a disposición de la producción de mercancías y plusvalor, radica en que tanto el trabajo como los medios de producción ${ }^{11}$ deben haber sido previamente transformados en capital. Marx (2013), en su célebre capítulo XXIV de El Capital, sobre "la llamada acumulación originaria"12", explica cómo es que "la conquista, el sojuzgamiento, el homicidio motivado por el robo: en una palabra, la violencia (p. 892)", son aspectos fundamentales en la conformación de dichas precondiciones para la existencia del capital como tal:

\begin{abstract}
La relación del capital presupone la escisión entre los trabajadores y la propiedad sobre las condiciones de realización del trabajo. Una vez establecida la producción capitalista, la misma no sólo mantiene la división sino que la reproduce a escala cada vez mayor. El proceso que crea a la relación del capital, pues, no puede ser otro que el proceso de escisión entre el obrero y la propiedad de sus condiciones de trabajo, proceso que por una parte, transforma en capital los medios de producción y de subsistencia sociales, y por otra convierte a los productores directos en asalariados (Marx 2014: 893).
\end{abstract}

De esta manera, se crean las condiciones para la existencia de las relaciones sociales, de clase, metabólicas y de producción que requiere el capital. A los sujetos "liberados" de los medios de trabajo y subsistencia ${ }^{13}$ no les queda ninguna otra posesión más que su mera fuerza de trabajo, la cual están obligados a vender al poseedor del capital, a manera de cualquiera otra mercancía, para

\footnotetext{
${ }^{11}$ Que no son otra cosa mas que naturaleza no humana, previamente transformada por el trabajo humano, mas no necesariamente pre-transformada inicialmente en cuanto a su materialidad, mas sí en cuanto a las relaciones de propiedad.

${ }^{12}$ Si bien, Marx parece ubicar el proceso de "acumulación originaria" como un acontecimiento histórico específico ocurrido paulatinamente a lo largo de los siglos subsecuentes a la caída del régimen feudal, bajo la forma de grandes cercamientos de tierra en Europa, varios autores consideran que, en realidad, los procesos de acumulación de capital vía despojo (Harvey 2004), son un proceso inherente y continuo a lo largo de la historia de la reproducción del capital (De Angelis 2012).

${ }^{13}$ Éstos últimos, los cuales no son otra cosa mas que, fundamentalmente, aunque no sólo, son la naturaleza-tierra.
} 
obtener los recursos mínimos - mediando el salario - para sobrevivir y reproducirse. A su vez, se crean las relaciones de propiedad capitalistas, en las cuales la tierra y la naturaleza son susceptibles de incorporarse al sistema de producción de mercancías, es decir, de ser transformadas en capital. La naturaleza-tierra pasa de ser mero medio de vida - conjunto y trama de vida en sí misma - y medio de producción ${ }^{14}$ para ser tratada como mercancía y/o transformada directamente en capital ${ }^{15}$.

Tras esta escisión, la vida en su conjunto, la naturaleza humana y no humana, son separadas entre sí y del proceso de reproducción de la vida misma (en sí y para sí), para ser sometidas al proceso de producción de mercancías. La naturaleza-tierra y el trabajo (trabajador como trabajo vivo y sujeto en sí y para sí), fuentes de toda riqueza, materia y fundamento de toda forma de vida, quedan de esta manera desvinculados de los ciclos vitales en sí mismos, para ser subsumidos a los ciclos de producción de mercancías y plusvalor. La precondición para las existencia de la relación de capital, es la precondición para la existencia del (geo-socio)metabolismo del capital: la disposición de la materia y energía de la naturaleza humana y no humana (trabajo y "recursos naturales") para la producción de mercancías y plusvalor.

Es mediante la explotación de la fuerza de trabajo - que no es más que el gasto de fuerza física (trabajo-energía) por parte del trabajador - la forma fundamental en la que el capital incorpora la energía humana a su metabolismo introduciendo ésta en los procesos de valorización del valor. El capital, para reproducirse, requiere de la vida, de la fuerza vital de los trabajadores, "es trabajo muerto que sólo se reanima, a la manera de un vampiro, al chupar trabajo vivo, y que vive tanto más cuanto más trabajo vivo chupa" (Marx 2014: 279-280).

A lo largo de su obra, Marx hace referencia al trabajo vivo de distintas maneras, refiriéndose a éste como capacidad viva de trabajo: fuerza de trabajo como tal, trabajo subjetivo, corporalidad activa del sujeto que trabaja (Dussel 1994). El trabajador mismo como corporalidad de sujeto que despliega su energía creativa en el trabajo presente ${ }^{16}$. El trabajo vivo se opone al trabajo

\footnotetext{
${ }^{14}$ En el sentido general de producción mediante trabajo concreto de valores de uso.

${ }^{15}$ En términos de Polanyi (1989) la tierra y el trabajo (junto con el dinero) son "mercancías ficticias", en el sentido de que son tratadas como mercancías, mas es imposible producirlas como tales, es decir, como un objeto producido para su venta. En términos de las claves que hemos venido desarrollando, el capital requiere producir las condiciones para que la tierra y el trabajo sean susceptibles de ser tratados como mercancías mediante la realización de separaciones, en este caso, la separación de los sujetos humanos respecto de la tierra-naturaleza no humana, en y de la cual viven los primeros (la llamada acumulación originaria). Respecto a su tratamiento de unos u otros como capital o como mercancía, en determinado momento podrá ser tratada de una u otra manera (que se puede explicar desde la fórmula de Marx respecto al ciclo D-M-D') ya que, bajo las reglas del capital, el trabajo (al principio del ciclo como única propiedad del trabajador) y la tierra y otros medios de producción (nunca bajo propiedad del trabajador) en determinado momento pueden ser comprados y vendidos, mas su poseedor en el momento de la producción, el capitalista que las ha comprado, pasa a incorporarlas como parte del capital variable y el capital fijo respectivamente.

${ }^{16}$ El tratamiento y desarrollo de la categoría de trabajo vivo está disperso en los Grundrissse de 1857, el Urtext de 1858, los manuscritos del 1861-1863 y 1863-1865 y en el Tomo I de El Capital. La definición que aquí se hace de trabajo vivo está fundamentado en el análisis y revisión bibliográfica que el autor hace de las obras antes mencionadas en el capítulo
} 
muerto como trabajo pretérito objetivado. Es transformado en trabajo muerto en el momento de la producción (de mercancías ${ }^{17}$ ). Este trabajo objetivado se expresa en el valor contenido en una mercancía, lo mismo en el dinero, en su rol de equivalencia a cualquier forma de mercancía. El trabajo objetivado, se ve expresado a su vez en el salario: trabajo muerto cristalizado en dinero como producto de un trabajo pretérito. Éste es otorgado al trabajador a cambio de su trabajo vivo para que pueda obtener los insumos vitales - aunque sean mínimos - para su reproducción y, por ende, seguir invirtiendo su trabajo vivo - a cambio de otro salario - sobre los medios de producción capitalista para la producción de mercancías y la generación de valor - trabajo muerto u objetivado $^{18}$.

De la misma manera que la forma general de trabajo como trabajo concreto - y la forma de la riqueza como valor de uso - preceden a la existencia del trabajo como trabajo abstracto productor de valor, así como a la riqueza bajo forma mercancía - valor de uso y valor a la vez; la existencia del trabajo como trabajo vivo es condición necesaria y fuente de todo valor, más el primero precede a la existencia del último.

Ahora bien, cabe recalcar que la extracción de plusvalor, es decir, la cantidad de trabajo vivo siendo objetivado, la energía vital propia del trabajador como sujeto vivo, menos el salario trabajo muerto como expresión de un trabajo pretérito, otrora vivo y ahora objetivado - tiene repercusiones considerables sobre la calidad y el tiempo de vida del sujeto: sobre su existencia como sujeto vivo.

Desde una lectura metabólica, el sujeto trabajador como sujeto vivo sufre estas consecuencias debido a la disparidad entre la calidad, cantidad y tiempo de trabajo vivo - energía objetivándose en valor-mercancía como trabajo muerto (cuyo despliegue implica un desgaste físicocorporal-mental) y la cantidad y calidad de materia-energía retornada en forma salario a la que le es posible acceder para la reparación óptima de sus condiciones vitales para el trabajo: tiempo y espacio en calidad y cantidad suficientes para el descanso, esparcimiento y ocio, entre otras actividades necesarias para la reproducción - lo suficientemente duraderos, amplios, acondicionados y salubres; calidad y cantidad de nutrientes y agua necesarias para la reparación y el despliegue del

10 de su Historia de la filosofía latinoamericana y filosofía de la liberación (1994). Según el autor, la categoría de trabajo vivo sería así el concepto (y también la categoría) más simple, más originaria, la supuesta en todo el discurso dialéctico de Marx.

${ }^{17}$ El capitalismo no es el único modo de producción donde existe la forma mercancías, mas sí el único modo de producción donde predomina dicha forma.

${ }^{18}$ Cabe recalcar lo mencionado antes, respecto a que la condición necesaria para que el trabajo esté disponible para su venta, el trabajador habrá de estar separado previamente de los medios de producción. 
trabajo vivo, etc. ${ }^{19}$. Retomando la metáfora del vampiro, podemos decir que, el ritmo e intensidad con la que el vampiro chupa - extrae - sangre - trabajo vivo - es considerablemente mayor a los ritmos de recuperación y las necesidades metabólicas del sujeto vivo.

Lo planteado hasta el momento nos permite hacer una extrapolación de la metáfora de Marx respecto al capital como vampiro - respecto al trabajo vivo -, hacia el capital como vampiro respecto a la naturaleza no-humana o naturaleza-tierra, aunque de una manera cualitativamente distinta. Así como el capital procura apropiarse de la mayor cantidad de trabajo vivo para la producción de mercancía-valor, lo mismo hace con la naturaleza no humana, sea esta especies vivas o elementos "abióticos", cuya materialidad pasará a conformar la materialidad de las mercancías y los medios de producción, o habrá de ser transformada en energía para el funcionamiento cada vez más automatizado de estos últimos, para poner en marcha el sistema de distribución de mercancías y valores, o para ser transformada en un bien de consumo doméstico ${ }^{20}$.

Si bien la naturaleza no humana como tal no produce valor, la materialidad de ésta es condición necesaria para la creación de valores de uso, y por ende de las mercancías en su doble carácter: ningún trabajo útil susceptible de ser valorizado - mediante apropiación de trabajo vivo es vertido al vacío, sino sobre la materialidad de la naturaleza en su conjunto. Ahora bien, la naturaleza no humana no sólo precede en su existencia al capital, sino incluso a la especie humana. Vista tanto como trama de la vida en su conjunto, como diversidad de comunidades bióticas, o como multiplicidad de especies vivas, la naturaleza como tal despliega a través de su corporeidad material actividad creativa para la reproducción de la vida en su conjunto - o cada especie para la reproducción de sí misma. Respecto a esta naturaleza no humana, cuya existencia viva precede a su existencia como mero objeto ${ }^{21}$; de la misma manera que el capital procura extraer "hasta la última gota de sangre, tendón o músculo" del trabajo vivo del trabajador - de su existencia y actividad vital y corpórea como sujeto vivo, lo mismo hace con la naturaleza no humana, apropiándose de su corporeidad como existencia viva, de la materia y energía que la constituyen para transformarla en "naturaleza muerta": en la corporeidad de la mercancía como objeto producido que contiene valor.

La naturaleza como trama, como conjunto diverso e interdependiente de comunidades bióticas y elementos "abióticos" necesarios para la vida que en su conjunto despliegan actividad

\footnotetext{
${ }^{19}$ Estos aspectos son desarrollados en el capítulo VIII del capital, en lo referente a la jornada de trabajo.

${ }^{20}$ Ya sea un bien de consumo no plenamente mercantilizado subsidiado por el estado para facilitar el acceso de los núcleos domésticos a la energía; ya sea directamente como mercancía, subsumida a las lógicas de compra, venta y especulación de los mercados nacionales e internacionales, como ha venido ocurriendo en Latinoamérica los últimos años con la privatización de la infraestructura productiva y distribuidora de la energía, otrora propiedad de la nación.

${ }^{21}$ Incluso como mero valor de uso, aunque en las sociedades en las que no predomina la racionalidad instrumental respecto a la naturaleza no humana, ni la lógica del valor, los elementos de dicha naturaleza rara vez son tratados como meros objetos.
} 
vital y creativa, queda capturada así bajo la forma mercancía, como materialidad viva transformada en mero objeto contenedor de valor. Y así como el ritmo de la producción - tendencialmente el más rápido posible - tiene repercusiones en la existencia viva de los sujetos humanos, éste tiene repercusiones sobre la vida en su conjunto, de la cual depende. No solo por la extracción de la materia-energía de la trama de la vida, sino también por la materialidad de la naturaleza devuelta en forma de desechos del proceso de extracción, producción y consumo de las mercancías.

En este sentido podemos decir que el metabolismo del capital es fundamentalmente extractivo. Puesto que el móvil de la producción de objetos bajo la forma mercancía es la mayor ganancia, que es mayor cuanto más extrae plusvalor; el capital tiende a intensificar de manera progresiva, en la medida de lo posible, el proceso de producción. Debido a que la materialidad de las mercancías no es otra que trabajo humano y materia-energía adquirida de la naturaleza no humana; la reproducción del capital, el fundamento de su funcionamiento metabólico, implica de la extracción de la mayor cantidad posible de trabajo-energía del entramado de vida.

Los requerimientos metabólicos del capital van in crescendo, por lo éste necesita de intensificar cada vez más las formas de extracción y explotación de la naturaleza humana y no humana. Ya sea mediante la innovación tecnológica, que le permite extraer y transformar materia a una escala y ritmo mayor; ya sea mediante la reorganización y desarrollo del proceso social de producción que le permita tener a su disposición la mayor cantidad de trabajo posible; ya sea mediante nuevos ciclos de despojo y sometimiento que le permitan tener a su disposición el trabajoenergía de sociedades y territorios que hasta el momento habían permanecido al margen o parcialmente al margen de los ciclos de producción de mercancías y valorización del valor ${ }^{22}$. También, mediante la subsunción de ámbitos de la vida social y natural que hasta el momento habían permanecido "fuera" de los procesos de reproducción del capital ${ }^{23}$.

Debido a estos requerimientos metabólicos paulatinamente en crecimiento, cuya dinámica no tiene otro límite que el de las condiciones de producción existentes en un momento dado desarrollo tecnológico, disponibilidad de naturaleza y trabajo lo más barato posibles, el capital requiere reproducir y ensanchar la brecha de la separación al interior de los ámbitos de la vida previamente subsumidos, así como de efectuar separaciones ex novo (De Angelis 2012) sobre sociedades y territorios hasta dicho momento no subsumidos o no plenamente subsumidos

\footnotetext{
${ }^{22}$ La fuerza de trabajo incorporada a las sociedades capitalistas, mas desempleada, es también parte del proceso de extracción-explotación de trabajo vivo para la generación de plusvalor, puesto que al hacer presión a la baja en los precios de la fuerza de trabajo activa, permite a los empleadores retribuirles un salario mucho menor.

${ }^{23}$ La expansión del capital hacia lo ancho y lo profundo del entramado de vida, la aceleración del metabolismo del capital no se debe únicamente a su necesidad del aumento de la productividad, sino también, como condición necesaria para no sucumbir bajo el peso de sus contradicciónes, postergando éstas al mismo tiempo que las profundiza.
} 
(Gutiérrez 2015; Gutiérrez y Salazar 2015; Gutiérrez, Navarro y Linsalata, 2016): el movimiento del capital a través de la trama de la vida radica en una dinámica tendencialmente totalizante en términos tanto extensivos como intensivos.

El modo de producción capitalista no es, pues, solamente un modo de producción y consumo de objetos bajo la forma mercancía, sino también una forma de reproducción social que produce relaciones sociales, subjetividades, espacios, territorios y naturaleza: produce y reproduce de manera ampliada las condiciones de producción capitalista. Ello de tal manera que le permita tener a su disposición la mayor cantidad de trabajo-energía para reproducirse: alimentarse, desarrollarse, crecer y expandirse. El geo-socio-metabolismo del capital es una ecología mundo, que requiere de reorganizar y transformar radicalmente las relaciones metabólicas del entramado de vida en su conjunto. En este sentido, el capital actúa y se despliegue a través de la trama de la vida (Moore 2015), desplegando desde sus medios cierta capacidad de energía-materialidad, mediante la cual efectúa separaciones - por ejemplo, la separación del sujeto vivo respecto a la naturaleza-tierra - e interponiendo mediaciones (Gutiérrez \& Navarro 2018) - por ejemplo, los medios de producción previamente privatizados y la "retribución" de salario a cambio de la reactualización del proceso de trabajo vivo objetivándose.

Existe pues una contradicción en la relación metabólica del capital, puesto que, al mismo tiempo que su reproducción depende de la naturaleza humana y no humana pues ésta conforma la materialidad de las mercancías. Su ambición - "necesidad" - de extraer la mayor cantidad de trabajo-energía posible se realiza "socavando, al mismo tiempo, los dos manantiales de toda riqueza: la tierra y el trabajador", socavando al mismo tiempo las condiciones de existencia de toda vida posible. En la relación metabólica del capital está inscrita su contradicción con la vida, puesto que depende de ella al mismo tiempo que destruye las condiciones de su reproducción.

\section{ALGUNAS REFLEXIONES FINALES PARA PENSAR LO "MORTÍFERO" DEL CAPITAL Y SU DINÁMICA EXTRACTIVA}

Hasta el momento hemos abordado cómo es que en la lógica del capital que de entrada se presenta como un modo de producción de riqueza bajo la forma de mercancías está inscrita su dinámica extractivista. El capital para su reproducción requiere de trastocar radicalmente los flujos metabólicos de la trama de la vida para que tanto la naturaleza no humana como el trabajo sean susceptibles de ser transformadas en mercancía, dando así cuerpo (la materialidad del objeto) y sustancia (el valor extraído del trabajo) a ésta. En su movimiento tendencialmente totalizante, 
extensivo e intensivo, procura de apropiarse de la mayor cantidad de trabajo al máximo ritmo posible, destruyendo progresivamente las condiciones para su reproducción.

Ello no debería preocuparnos si la contradicción pusiera en riesgo solamente la existencia del modo y las relaciones de producción capitalista. Sin embargo, a esta altura de la crisis ecológico-civilizatoria (Machado 2013), vemos que lo que se encuentra amenazado por el capital y su dinámica de expansión extractiva es la existencia de la vida misma. Toda fuente, componente, condición y composición de toda forma de vida humana y no humana. Ante el inevitable agotamiento de la "naturaleza barata" (Moore 2015), el capital intenta postergar a costa de lo que sea -de la vida misma-, la amenaza cada vez más cercada de una crisis de escasez o subproducción, la cual es fruto de su propia contradicción entre capital y naturaleza o capital-vida. Con tal de evitar caer bajo el peso de esta contradicción, ha expandido la frontera extractiva a lo largo y ancho del orbe, al mismo tiempo que ha desarrollado tecnologías aún más destructivas que le permitan extraer "hasta la última gota de sangre" de la naturaleza-tierra. Ejemplo de ello es la implementación de la minería a cielo abierto y el fracking sobre yacimientos no convencionales.

El trastocamiento que la dinámica tendencialmente totalizante y expansiva, geo-territorial y socio-metabólica del capital ha efectuado progresiva y exponencialmente de manera radical en los flujos material-energéticos de la trama de la vida es preocupante. Al respecto, Donna Haraway (2016: 17), retomando a Ana Tising, observa que la dinámica destructiva de la lógica del capital "pude eliminar la mayor parte de los refugios a partir de los cuales diversos grupos de especies (con o sin personas) pueden reconstituirse después e eventos extremos (como la desertización, o la deforestación $o, o . .) ”$.

El capital y sus representantes - los capitalistas individuales - parecieran ser ciegos a la catástrofe a la que su propia dinámica está arrastrando hacia la destrucción tanto a la humanidad como a toda posibilidad de vida. Más allá de toda negación al respecto, encontramos dicha “desconsideración en el imperativo ético que pone como fin en sí mismo la realización de ganancia:

\begin{abstract}
Si buscamos la dimensión ética en todo este asunto, la encontramos en el compromiso incondicional del capitalismo con su propia continua reproducción expansiva: un capitalista que se dedica incondicionalmente al impulso auto-expansivo capitalista está efectivamente dispuesto a ponerlo todo, incluyendo la supervivencia de la humanidad, en juego, no para cualquier ganancia o meta "patológica" sino por el bien de la reproducción del sistema en sí mismo. Fiat profitus pereat mundus (dejemos que los beneficios se hagan, aunque el mundo perezca) es lo que presumimos es su lema (Žižek 2017).
\end{abstract}

En la lógica extractiva del capital, el despojo, la separación entre los productores respecto a sus medios de existencia, o dicho de otra manera, la separación de las sociedades respecto a las bases y condiciones materiales de reproducción de la vida - ya sea mediante el despojo o mediante 
la destrucción de éstas -, está a su vez relacionado con la separación, desestructuración y destrucción de las condiciones sociales, culturales, simbólicas y políticas de la reproducción de la vida de diversos grupos humanos; así como en la desestructuración de las condiciones ecológicometabólicas de la vida en su conjunto.

En este contexto, los proyectos extractivos, también denominados "proyectos de muerte" (minería a cielo abierto, fracking, hidroeléctricas, entre otros) tienen diversas repercusiones: escasez y envenenamiento del agua, desvío de los embalses de los ríos, contaminación e inundación de tierras, proliferación de enfermedades, intoxicación de animales y humanos, muerte de plantas y un largo etcétera. Sin embargo, en términos metabólicos, lo preocupante radica en las modificaciones radicales que estos proyectos tienen sobre los flujos de materia-energía de la trama e la vida, los cuales causan desde daños a la salud de plantas, animales y humanos, hasta el socavamiento de las bases materiales para la reproducción de la vida humana y no humana.

Ahora bien, para concluir y en atención al desarrollo de la dinámica inherentemente extractiva-destructiva del capital, me aventuro a concluir que, el Gran Proyecto de Muerte no es la minería a cielo abierto, ni la extracción de hidrocarburos mediante fracking, ni las grandes hidroeléctricas y parques eólicos. Tampoco los transgénicos y los grandes monocultivos para la producción de biocombustibles o cualquier otro megaproyecto de corte extractivo. Todos estos son componentes esenciales en el metabolismo del Gran Proyecto de muerte: el capital, cuyo fundamento (re)productivo y geo-socio-metabólico radica en la extracción imparable e in crescendo de la materia-energía-trabajo de la naturaleza humana y no humana.

Los representantes del capital que promueven los proyectos extractivos (de muerte) niegan los estragos del modo de producción (y extracción) dominante y la matriz energética actual, o se centran en el falaz discurso del desarrollo sustentable que tiende a normalizar y banalizar la crisis ecológica, al tiempo que ofrece soluciones ficticias a esta, proponiendo soluciones ficticias (como la "minería sustentable" o las hidroeléctricas como presunta fuente de "energía renovable". También están los que se posicionan desde los discursos del progreso, que si bien, no niegan las posibles repercusiones, tampoco las nombran. Y si las nombran, las minimizan bajo el argumento de que el progreso y la industria son necesarios para la sociedad, e incluso para la vida misma.

Sin embargo, en medio de las apariencias y mediaciones que, bajo las relaciones del capital ocultan la catástrofe, el sentido común de disidencia que está siendo producido por pueblos y comunidades en resistencia por todo Latinoamérica - y otras partes del mundo - contra los proyectos extractivos, está visibilizando todo aquello que ha sido negado. Desde este sentido, desde el cual se enuncia al extractivismo como antagónico a la vida, la noción de "proyectos de muerte", más que 
una buena metáfora, es una amenaza real que se cierne sobre la materialidad que permite la reproducción de la vida: vale la pena tomar en serio la advertencia.

\section{REFERENCIAS:}

CAPRA, Fritjof. 1998. La trama de la vida. Una nueva perspectiva de los seres vivos. Barcelona: Anagrama.

DE ANGELIS, Massimo. 2012. "Marx y la acumulación primitiva. El carácter continuo de los "cercamientos" capitalistas". Theomai (26).

DUSSEL, Enrique. 1994. Historia de la filosofía latinoamericana y filosofía de la liberación. Bogotá: Nueva América.

ECHEVERRÍA, Bolívar. 1998). Valor de uso y utopía. México: Siglo XXI.

ECHEVERRÍA, Bolívar. 2010. Definición de la cultura. México: Fondo de Cultura Económica.

GUTIÉRREZ, Raquel. 2015. Horizonte comunitario-popular. Antagonismo y producción de lo común en América Latina. Puebla, México: ICSyH-BUAP.

GUTIÉRREZ, Raquel y Mina Navarro. 2018. "Claves para pensar la interdependencia desde la ecologia y losFeminismos”. Bajo el Volcán (28).

GUTIÉRREZ, Raquel, Mina Navarro y Lucía Linsalata. 2016. "Producir lo común para reproducir la vida: claves para repensar lo político" (inédito).

GUTIÉRREZ, Raquel y Huáscar Salazar. 2015. "Reproduccion comunitaria de la vida. Pensando la transformación social en el presente". El Apantle. Revista de Estudios Comunitarios, I (1): 15-50.

HARAWAY, Donna. 2016. “Antropoceno, capitaloceno, plantacionoceno, cthulhuceno : generando relaciones de parentesco". Revista Latinoamericana de Estudios Críticos Animales, I, 15-26.

HARVEY, David. 2004. El Nuevo Imperialismo. Madrid: Akal Ediciones.

LINSALATA, Lucia. 2011. Valor de uso, Poder y Transformación Social. México: Casa de Ondas.

MACHADO ARÁOZ, Horacio. 2013. “Crisis ecologica, conflictos socioambientales y orden neocolonial: Las paradojas de NuestrAmerica en las fronteras del extractivismo”. REBELA. Revisa Brasileira de Estudios Latino-Americanos, 3(1), 118-155.

MARX, Karl. 2013. El Capital. Tomo I (2.a ed., Vol. 3). México: Siglo XXI.

MARX, Karl. 2014. El Capital. Tomo I (1.a ed., Vol. 1). México: XXI.

MOORE, Jason. 2015. Capitalism in the web of life. Ecology and the Accumulation of Capital. Londres: Verso. 
O’CONNOR, James. 2001. Causas naturales. Ensayos de marxismo ecológico. México: Siglo XXI.

POLANYI, Karl. 1989. La gran transformación. Crítica del liberalismo económico. Madrid:

Ediciones la Piqueta.

ŽIŽEK, Slavoj. 2017. Slavoj Žižek: Lecciones del "Airepocalipsis. Disponible en <

https://diem25.org/slavoj-zizek-lecciones-del-airepocalipsis/ > recuperado 1 de diciembre de 2018.

\section{AUTOR:}

\section{Francisco Javier Hernández Hernández}

Antropólogo por la Universidad de Guadalajara, Maestro en Sociología por el Instituto de Ciencias Sociales y Humanidades de la Benemérita Universidad Autónoma de Puebla (ICSyH-BUAP).

E-mail: javiherh.anthropos@gmail.com 